УДК 597/599

Пісоцька В.В. https://orcid.org/0000-0003-0916-4223

\title{
ОСОБЛИВОСТІ ФОРМУВАННЯ ОРНІТОЦЕНОЗІВ ЗАЛІЗНИЧНИХ ЛІСОСМУГ ХАРКІВСЬКОЇ ОБЛАСТІ
}

\author{
(C) Пісоцька В.В. \\ Харківський національний педагогічний університет імені Г.С. Сковороди \\ lerapisocka@ukr.net \\ https://doi.org/10.34142/2708-5848.2020.22.2.10
}

Залізничні лісонасадження - унікальні біотопи зі значним антропогенним навантаженням, що значно впливає на видове, кількісне різноманіття птахів, поведінкові реакції. Дослідження проводилися в різних типах лісосмуг: штучні лісонасадження вздовж колій, що межують 3 агроценозом; штучні лісонасадження вздовж колій, що межують 3 водними об'єктами; штучні лісонасадження вздовж колій, що межують 3 населеними пунктами та антропогенними спорудами. В ході проведених досліджене у різних типах лісосмуг вздовж залізничних шляхів зареєстровано 59 видів птахів. Переважають представники ряду Горобцеподібні. Видове різноманіття птахів штучних лісонасаджень вздовж колій, що межують з агроценозом (лісосмуга № 1) представлено 46 видами. Домінує Sturnus vulgaris L. (147.2 пари), Turdus philomelos Brehm. (128.9 пари), Motacilla flava L.(102.3 пари) та інші. 50 видів птахів характерні для штучних лісонасаджень вздовж колій, що межують 3 водними об'єктами (лісосмуга 2). Домінантними видами є Corvus cornix L. (157 пари), Pica pica L. (150 пар) Sturnus vulgaris L. (144.4 пари) Parus major L. (142.2 пари). Орнітокомплекс штучних лісонасаджень вздовж колій, що межують 3 населеними пунктами та антропогенними спорудами (лісосмуга 3) представлений 44 видами. Домінантними видами є Hirundo rustica L. (163 пари), Parus major L. (161.4 пари), Pica pica L. (157.7 пари), Corvus cornix L.(156.9 пари), Passer domesticus L., (129.9 пари) та інші. Проаналізовано показники коефіцієнта подібності Жаккара та Соренсена. Показники визначених коефіцієнтів свідчать про подібність видового складу птахів різних типів лісонасаджень вздовж залізничних колій. Високий показник подібності спостерігається між штучними насадженнями вздовж колій, що межують 3 агроценозом та штучними насадженнями вздовж колій, що межують 3 населеними пунктами та антропогенними спорудами (коефіцієнт Жаккара дорівнює 0.91 та коефіцієнт подібності Соренсена дорівнює 0.95 відповідно).

Ключові слова: итучні лісосмуги вздовж колій, чисельність птахів, орнітоценоз, оцінка чисельності, антропогенний вплив.

Транспортний комплекс $є$ одним 3 потужних чинників трансформації популяцій живих організмів. Важливими екологічними особливостями транспортних систем є: антропогенна трансформація біотопів. Насамперед шкідливі викиди в атмосферу, шумове навантаження і смертність через рух транспорту. Особливостями таких біотопів $є$ фрагментація та порушення міграційних шляхів. Дослідження екологічної та генетичної диференціації популяцій внаслідок їхньої просторової ізоляції транспортними комплексами займає чільне місце у публікаціях закордонних вчених, але ці дослідження стосуються в, більшій мірі, автотранспортних систем $[3,6,7,12]$. Регулярно здійснюються заходи 3 охорони популяцій диких тварин, що підлягають такому впливу. У біотопах, що межують з транспортними шляхами спостерігаються екологічні відмінності порівняно 3 природними біоценозами. Рух транспорту, як антропогенний фактор, радикально впливає на характер розмноження, міграцій, вікову, статеву, просторову структуру популяцій, темпи народжуваності та смертності живих організмів [6, 7, 10]. Залізничні лісо-насадження - унікальні біотопи зі значним антропогенним навантаженням, що значно впливає на видове, кількісне різноманіття птахів, поведінкові реакції. Даний тип штучних лісонасаджень почали створювати 1951 р. і до тепер, за даними Укрзалізниці проводилось достатньо лісогосподарських, агротехнічних, лісовідновних і охоронних заходів. Більш ніж за піввікове існування досліджувані біотопи мають специфічне значення у екологічній мережі місцевості. Впливають на формування унікальних антропогенно адаптованих орнітоценозів 
$[6,7,10]$. Проте в Україні ця проблема залишається не вивченою і потребує масштабного дослідження. Тому вони $\epsilon$ актуальними та доцільними. Метою проведення досліджень $є$ вивчення

\section{МАТЕРІАЛИ І МЕТОДИ}

Дослідження орнітофауни штучних лісосмуг вздовж залізничних шляхів проводили протягом 2018-2020 років. Вздовж залізничної магістралі сполученням Харків-Лисичанськ (Південна залізниця). Маршрутні обліки птахів здійснювали у гніздовий період $3 \quad 1.04$ по 30.06 за загальноприйнятою методикою [11]. Протягом репродуктивного періоду гніздові території птахів виявляли як по голосу, так i за візуальними зустрічами окремих особин. Обліки проводили, як правило, у гніздовий період через 1,5-2,0 години після світанку. Щорічно проводили 2-3 обліки в кожному біотопі. Загальна протяжність маршруту вздовж залізничної колії становить 100 км. Сумарна протяжність кожної лісосмуги близько 30 км. Дослідження проводили з використанням вело- та автотранспорту. Кожного самця, що співає вважали за пару. На маршруті реєстрували всіх особин без врахування

\section{РЕЗУЛЬТАТИ}

В ході проведених досліджене у різних типах лісосмуг вздовж залізничних шляхів зареєстровано 59 видів птахів. Переважають представники ряду Passeriformes (табл.1). Видове різноманіття птахів штучних лісосмуг вздовж колій, що межують 3 агроценозом (лісосмуги №1) представлено 46 видами. Для штучних видового складу та чисельності птахів лісосмуг вздовж залізничних колій в територіальних межах Харківської та Луганської областей.

відстані до них, що обумовлено невеликою шириною лісосмуг, більшість 3 яких мають 2-3 ряди насаджень та ширину 20 м, зрідка - до 30 м, що робить можливим облік усіх птахів. В ході досліджень виділено три групи лісосмуг: штучні насадження вздовж колій, що межують 3 агроценозом (лісосмуга 1); штучні насадження вздовж колій, що межують 3 водними об'єктами (лісосмуга 2); штучні насадження вздовж колій, що межують з населеними пунктами та антропогенними спорудами (лісосмуга 3).

Чисельність птахів проаналізована за п’ятибальною шкалою $[1,2,3,8,9]$. «Дуже рідкісні» - 1-6 особин або $0.01 \%-0.07 \%$ від загальної кількості; «Рідкісні» - 7-36 особин (0.08\%-0.45\%); «Присутні» - 37213 особин (0.46\%-2.80\%); «Звичайні»214-1275 особин (2.81\%-16.73\%); «Чисельні» - понад 1276 особин (16.74\%$100 \%)$.

лісосмуг вздовж колій, що межують 3 водними об'єктами (лісосмуга №2) характерними є 50 видів птахів. Орнітоценоз штучних лісосмуг вздовж колій, що межують 3 населеними пунктами та антропогенними спорудами (лісосмуга №3) представлений 44 видами. 
Таблиия 1

Видовий та кількісний склад птахів залізничних лісосмуг (пари)

\begin{tabular}{|c|c|c|c|c|c|c|c|}
\hline \multirow[b]{2}{*}{ Назва виду } & \multicolumn{2}{|c|}{ Лісосмуга 1} & \multicolumn{2}{|c|}{ Лісосмуг 2} & \multicolumn{2}{|c|}{ Лісосмуга 3} & \multirow{2}{*}{ 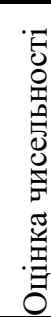 } \\
\hline & 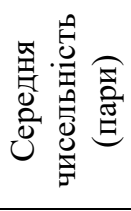 & 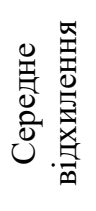 & 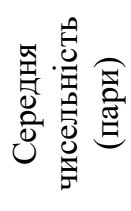 & 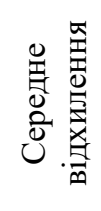 & 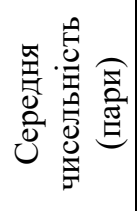 & 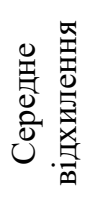 & \\
\hline Ixobrychus minutus L. & - & - & 13 & 0.2 & - & - & $\mathrm{R}$ \\
\hline Nycticorax nycticorax L. & - & - & 3.7 & 0.42 & - & - & $\mathrm{R}$ \\
\hline Egretta alba L. & - & - & 11 & 0.2 & - & - & $\mathrm{R}$ \\
\hline Egretta garzetta L. & $\overline{-1}$ & $\overline{-1}$ & 7.9 & 0.94 & 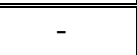 & 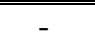 & $\overline{\mathrm{R}}$ \\
\hline Ardea cinerea L. & - & - & 26.5 & 4.1 & - & - & $\mathrm{P}$ \\
\hline Ardea purpurea L. & - & - & 19.8 & 3.28 & - & - & $\bar{P}$ \\
\hline Ciconia ciconia $\mathrm{L}$. & - & - & 13.2 & 0.96 & 6.2 & 1.08 & $\mathrm{R}$ \\
\hline Casarca ferruginea Pallas & - & - & 16.6 & 3.56 & - & - & $\overline{\mathrm{P}}$ \\
\hline Anas platyrhynchos L. & - & - & 32.1 & 2.72 & - & - & $\overline{\mathrm{P}}$ \\
\hline Anas crecca $\mathrm{L}$. & - & - & 24.2 & 7.32 & - & - & $P$ \\
\hline Milvus migrans Bod. & 2.7 & 0.96 & 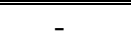 & 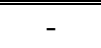 & 2.6 & 0.88 & $\mathrm{P}$ \\
\hline Accipiter gentilis L. & 1.6 & 0.48 & - & - & - & - & $\overline{\mathrm{V}}$ \\
\hline Buteo buteo L. & 4.5 & 1.4 & 6.9 & 0.54 & 5.9 & 0.72 & $\mathrm{P}$ \\
\hline Phasianus colchicus L. & 58.5 & 7.5 & 39.7 & 10.62 & 42.5 & 3.4 & $\mathrm{P}$ \\
\hline$\overline{F u l i c a}$ atra $L$. & - & - & 24.9 & 7.52 & - & - & $\overline{\mathrm{P}}$ \\
\hline Columba palumbus L. & 84.8 & 4.96 & 46.7 & 7.84 & 62.9 & 7.14 & $\bar{P}$ \\
\hline Streptopelia decaocto Frivaldszky & 28.9 & 4.28 & - & - & 62.7 & 6.62 & $\bar{P}$ \\
\hline Streptopelia turtur L. & 433.1 & 5.88 & 499.2 & 7.88 & 37.1 & 9.12 & $\overline{\mathrm{P}}$ \\
\hline Cuculus canorus L. & 29.9 & 1.3 & 24.1 & 1.92 & 16.3 & 6.5 & $\overline{\mathrm{P}}$ \\
\hline Asio otus L. & 42.1 & 6.88 & 27.8 & 5.24 & 29.6 & 5.72 & $\mathrm{P}$ \\
\hline Apus apus L. & 105.5 & 8.6 & 86.6 & 3.28 & 81.6 & 3.4 & $\overline{\mathrm{C}}$ \\
\hline Uрира ерорs L. & 47.4 & 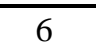 & 29 & 2.2 & 37.8 & 3.04 & $\bar{P}$ \\
\hline Jynx torquilla $\mathrm{L}$. & 108.4 & 9.92 & 64.9 & 10.48 & 86.9 & 5.92 & $\overline{\mathrm{P}}$ \\
\hline "Dendrocopos major L. & 113.3 & 6.76 & 101.9 & 7.28 & 108.2 & 13.4 & $\mathrm{P}$ \\
\hline Riparia riparia $\mathrm{L}$. & - & - & 31.6 & 1.6 & - & - & $\mathrm{P}$ \\
\hline
\end{tabular}


Біорізноманіття, екологія та експериментальна біологія, 2020, №2

\begin{tabular}{|c|c|c|c|c|c|c|c|}
\hline \multirow[b]{2}{*}{ Назва виду } & \multicolumn{2}{|c|}{ Лісосмуга 1} & \multicolumn{2}{|c|}{ Лісосмуг 2} & \multicolumn{2}{|c|}{ Лісосмуга 3} & \\
\hline & 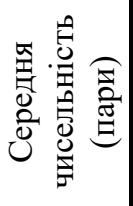 & 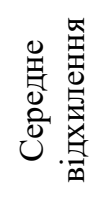 & 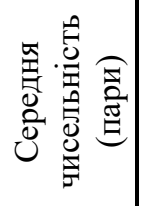 & 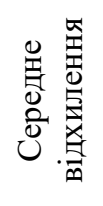 & 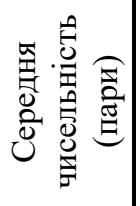 & 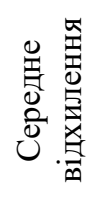 & 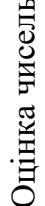 \\
\hline Hirundo rustica $\mathrm{L}$. & 26 & 8.1 & - & - & 163 & 28 & $\mathrm{P}$ \\
\hline Galerida cristata L. & $\overline{61.7}$ & 2.7 & - & - & 149.3 & 29.96 & $\mathrm{P}$ \\
\hline Anthus campestris L. & 65.8 & 9.08 & 118.2 & 35.96 & 77.9 & 24.06 & $\mathrm{P}$ \\
\hline Motacilla flava $\mathrm{L}$. & 10102.3 & 13.82 & - & $\overline{-1}$ & $\overline{54.9}$ & 2.1 & $\overline{\mathrm{C}}$ \\
\hline Motacilla alba $\mathrm{L}$. & 85.7 & 6.7 & 90 & 3.4 & $\overline{136.6}$ & 10.56 & $\bar{P}$ \\
\hline Lanius collurio $\mathrm{L}$. & 42.7 & 6.78 & 93.9 & 6.08 & 53.5 & 10.6 & $\mathrm{P}$ \\
\hline Lanius minor L. & 23 & 2.6 & 30 & 2.6 & - & - & $\mathrm{P}$ \\
\hline Oriolus oriolus L. & 66.3 & 8.64 & 49.9 & 3.96 & 35.8 & 11.56 & $\mathrm{P}$ \\
\hline Sturnus vulgaris $\mathrm{L}$. & 147.2 & 7.64 & 144.4 & 5.44 & 167.7 & 11.3 & C \\
\hline Garrulus glandarius L. & 80.1 & 7.52 & 77.6 & 18.16 & 62.2 & 11.72 & $\overline{\mathrm{C}}$ \\
\hline Pica pica $\mathrm{L}$. & 136.9 & 17.3 & 150 & 7.8 & 157.7 & 6.5 & $\mathrm{C}$ \\
\hline Corvus cornix $\mathrm{L}$. & 138.9 & 12.5 & 157 & 4.6 & 156.9 & 11.1 & $\mathrm{C}$ \\
\hline "Hippolais icterina $\mathrm{L}$. & 1.3 & 0.96 & - & - & - & - & $\overline{\mathrm{V}}$ \\
\hline Sylvia nisoria $\mathrm{L}$. & 67.4 & 6.08 & 116.8 & 28.68 & 51.9 & 5.12 & $\mathrm{P}$ \\
\hline Sylvia atricapilla $\mathrm{L}$. & 82.9 & 5.08 & 121.3 & 24.58 & 129.1 & 11.54 & $\mathrm{P}$ \\
\hline Ficedula albicollis Temm. & 73.7 & 8.7 & 68.3 & 3.04 & 59.3 & 2.96 & $\mathrm{P}$ \\
\hline Ficedula parva Pallas & 1.7 & 0.82 & - & - & 1.7 & 0.62 & V \\
\hline Saxicola rubetra $\mathrm{L}$. & $\overline{51.3}$ & $\overline{99.22}$ & $\overline{95.6}$ & 15.12 & $\overline{72.9}$ & 13.32 & $\bar{P}$ \\
\hline Erithacus rubecula $\mathrm{L}$. & 69 & 10.6 & 98.5 & 15.7 & 76.7 & 9.76 & $\overline{\mathrm{C}}$ \\
\hline Luscinia luscinia $\mathrm{L}$. & 62 & 5.8 & 88.7 & 9.08 & 37.6 & 2.4 & $\mathrm{P}$ \\
\hline Turdus pilaris $\mathrm{L}$. & $\overline{71.6}$ & 16.38 & 133.1 & 4.52 & 128.7 & 26.56 & $\overline{\mathrm{C}}$ \\
\hline Turdus merula $\mathrm{L}$. & 83.7 & 8.44 & 101.5 & 23.5 & 135.1 & 11.5 & $\mathrm{C}$ \\
\hline Turdus philomelos Brehm. & 128.9 & 7.7 & 98.4 & 22.84 & 134.2 & 9 & $\mathrm{C}$ \\
\hline Remiz pendulinus & $\overline{-1}$ & - & 16.6 & 3.44 & - & - & $\mathrm{P}$ \\
\hline Parus caeruleus $\mathrm{L}$. & 59.6 & 25.6 & 47.7 & 8.16 & 37.6 & 3.96 & $\mathrm{P}$ \\
\hline Parus major L. & 126.5 & 25.6 & $\overline{142.2}$ & 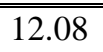 & $\overline{161.4}$ & 32.28 & $\overline{\mathrm{C}}$ \\
\hline Sitta europaea $\mathrm{L}$. & 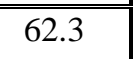 & (6.96 & $\overline{104}$ & 14.6 & 104.4 & 7.96 & $\overline{\mathrm{C}}$ \\
\hline Passer domesticus L. & 100.2 & 17.2 & 120.2 & 16.08 & 129.9 & 18.3 & $\mathrm{P}$ \\
\hline
\end{tabular}




\begin{tabular}{|c|c|c|c|c|c|c|c|}
\hline \multirow[b]{2}{*}{ Назва виду } & \multicolumn{2}{|c|}{ Лісосмуга 1} & \multicolumn{2}{|c|}{ Лісосмуг 2} & \multicolumn{2}{|c|}{ Лісосмуга 3} & \\
\hline & 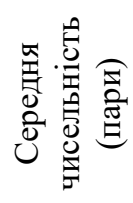 & 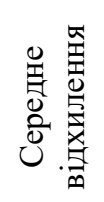 & 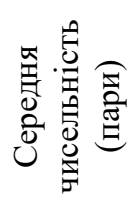 & 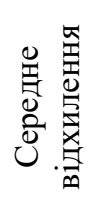 & 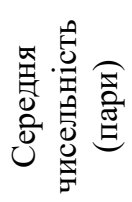 & 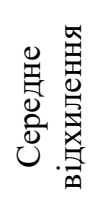 & 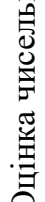 \\
\hline Passer montanus $\mathrm{L}$. & 121.6 & 10.12 & 110.7 & 25.62 & 84.5 & 2.3 & $\mathrm{C}$ \\
\hline Fringilla coelebs $\mathrm{L}$. & 127 & 8.2 & 148.6 & 5.2 & 116.7 & 2.82 & $\mathrm{C}$ \\
\hline Chloris chloris $\mathrm{L}$. & 85.7 & 11.16 & 112.6 & 13.56 & 108.6 & 13.68 & $\overline{\mathrm{C}}$ \\
\hline Carduelis carduelis L. & 90.7 & 19.98 & 108 & 21 & 124.8 & 25.64 & $\mathrm{C}$ \\
\hline$\overline{~ E m b e r i z a ~ c a l a n d r a ~ L . ~}$ & 433.9 & $\overline{9.7}$ & - & - & $4 \overline{45.8}$ & 3.88 & $\bar{P}$ \\
\hline Emberiza citrinella $\mathrm{L}$. & 115.2 & 13.24 & 123.2 & 13.36 & 79.3 & 4.1 & $\bar{C}$ \\
\hline
\end{tabular}

*C - звичайний, $\mathrm{P}$ - присутній, $\mathrm{R}$ - рідкісний, $\mathrm{V}$ - дуже рідкісний види

\section{ОБГОВОРЕННЯ}

Домінантними видами у лісосмузі № 1 є: Sturnus vulgaris L.(147.2 пар), Turdus philomelos Brehm. (128.9 пари), Motacilla flava L.(102.3 пари) та інші. Рідкісними видами є Hippolais icterina L. (1.3 пари), Accipiter gentilis L. (1.6 пари), Ficedula parva Pallas (1.7 пари). Високе біорізноманіття пояснюється сусідством біоценозу 3 агроценозом, наявності у лісосмузі польових видів птахів та можливістю додатково живитись у агроценозі (табл.1).

У лісосмузі 2 домінує Corvus cornix L. (157 пар), Pica pica L. (150 пар) Sturnus vulgaris L. (144.4 пари) Parus major L. (142.2 пари). Рідкісними видами є Nycticorax nycticorax L. (3.7 пари), Milvus migrans Bod. Характерною особливістю даного орнітоценозу є наявність в одному угрупованні лісових видів та птахів водно-болотного комплексу (табл.1).

Домінантними видами лісосмуги 3 є Hirundo rustica L. (163 пари), Parus major L. (161.4 пари), Pica pica L. (157.7 пар), Corvus cornix L.(156.9 пар), Passer domesticus L., (129.9 пар) та інші. Рідкісні види: Ficedula parva Pallas (1.7 пари), Milvus migrans Bod. (2.6 пари).
Характерною особливістю даного орнітокомплексу $\epsilon$ наявність у лісосмузі синантропних видів (табл.1).

Дослідження призалізничних лісосмуг проводилися на території Симбрівщини, в результаті яких виявлено 30 видів птахів, 3 щільністю населення 2900 ос.Ікм ${ }^{2}$. В результаті досліджень зроблено висновки, що характерною рисою лісосмуг $€$ значне біорізноманіття і висока щільність лісостепових і синантропних птахів [5].

Проаналізовано показники коефіцієнтів подібності Жаккара та Соренсена. Показники визначених коефіцієнтів свідчать про подібність видового складу птахів досліджуваних лісосмуг. Високий показник подібності спостерігається між штучними насадженнями вздовж колій, що межують 3 агроценозом та штучними насадженнями вздовж колій, що межують 3 населеними пунктами та антропогенними спорудами (коефіцієнт Жаккара дорівнює 0.91 та коефіцієнт подібності Соренсена дорівнює 0.95 відповідно) (табл.2).

видами. 50 видів птахів характерно для штучних лісосмуг вздовж колій, що межують 3 водними об'єктами. Орнітоценоз штучних лісосмуг вздовж колій, що межують 3 населеними пунктами та 
антропогенними спорудами представлений 44 видами. Спостерігається високий показник подібності досліджуваних біотопів (найвищий, характерний для лісосмуг вздовж колій, що межують 3 агроценозом та лісосмуг, що межують 3 населеними пунктами та антропогенними спорудами 3 показниками коефіцієнта Жаккара - 0.91 та коефіцієнта Соренсена - 0.95 відповідно).
Попри значний антропогенний тиск (шумове наван-таження, значну загазованість) на досліджувані біотопи спостерігається висока його продуктивність (значна кіль-кість та чисельність видів), що свідчить про високий рівень пристосування птахів до значних антропогенних навантажень та екологічну пластичність досліджуваних видів.

Таблиия 2

\title{
Подібність різноманіття птахів у різних типах лісосмуг
}

\begin{tabular}{|l|l|c|c|}
\hline $\begin{array}{l}\text { № } \\
\text { 3\п }\end{array}$ & Типи лісосмуг & $\begin{array}{c}\text { Коефіцієнт } \\
\text { подібності } \\
\text { Жаккара }\end{array}$ & $\begin{array}{c}\text { Коефіцієнт } \\
\text { подібності } \\
\text { Соренсена }\end{array}$ \\
\hline 1. & Лісосмуга1 та лісосмуга 2 & 0.62 & 0.77 \\
\hline 2. & Лісосмуга 1 та лісосмуга 3 & 0.91 & 0.95 \\
\hline 3. & Лісосмуга 2 та лісосмуга 3 & 0.64 & 0.78 \\
\hline
\end{tabular}

\section{Лimepamypa}

1. Ayubova, E. M. (2018). Ecological conditions of bird habitats in the south of Ukraine. Facta Universitatis Series: Working and Living Environmental Protection, 15 (3): 209-215.

2. Ayubova, E. M., \& Koshelev, V. A. (2019). The effect of pyrogenic succession on breeding birds of shelter belts in the North-Western part of the Azov sea region. Vestnik Zoologii, 53(2): 149-154.

3. Belik, V.P. (2009) Birds of artificial forests of the steppe Predka-vkaz'e: composition and formation of avifauna in arid conditions. Kryvyi Rih: Mineral.

4. Beier P., Majka D., Newell S., Garding E. (2008) Best Management Practices for wildlife Corridors Northern Arizona University.

5. Guzy A.I (1996) Seasonal peculiarities of the bird community of railway forest belts in Sambir district of Lviv region. Berkut 5 (1): 21-23

6. Luk'yanchuk N.G., Burmas O.V. (2006) Bioindikacijni metodi doslidzhen' virobnichoï diyal'nosti zaliznic'. Naukovij visnik NLTU Ukraïni : zb. nauk.-tekhn. prac'. L'viv. 48-51.

7. Lukyanchuk N.G., Ruda M.V. (2013) Shelter belts along the railway (history of environmental research and results). Scientific Bulletin of NLTU of Ukraine. Lviv. 110-117.

8. Lakin, G.F. (1986) Biometrics. Moscow: High School.

9. . Pesenko, Yu.A. (1982). Principles and methods of quantitative analysis in faunistic research. Moscow: Science.

10. Pisoc'ka V.V. (2020) Vidovij sklad ptahiv lisosmug zaliznichnoï magistrali Harkivs'koï oblasti. HII Mizhnarodna Internet-konferenciya Social'ni ta ekologichni tekhnologiï: aktual'ni problemi teoriï i praktiki Melitopol' 21-23 sichnya, roku. S. 190.

11. Ravkin E. S., Chelintsev N. G. (1990) Methodical recommendations for integrated route counting of birds. - M .VNII nature of the State Committee for Nature Protection of the USSR.

12. Trach I.A., Petruk V.G., Boychuk L.A.( 2015) The impact of transport systems on environmental safety of wilDdanimals populations. agriculture and forestry (1): 128-134.

\section{UDC 597/599}

\section{PECULIARITIES OF FORMATION OF ORNITHOCENOSES OF RAILWAY FORESTS OF KHARKIV REGION}

\author{
V.V. Pisotska
}

Railway plantations are unique biotopes with a significant anthropogenic load, which significantly affects the species, quantitative diversity of birds, their behavioral responses. The research was conducted in different types of forest belts: artificial afforestation along the tracks bordering the agrocenosis; artificial afforestation along the tracks adjacent to water bodies; artificial afforestation along the tracks bordering on settlements and anthropogenic structures. In the course of the study, 59 species of birds were registered in different types of forest belts along the 
railway tracks. Representatives of a number of Sparrows predominate. The species diversity of birds of artificial forest plantations along the tracks bordering the agrocenosis (forest belt № 1) is represented by 46 species. Among them, Sturnus vulgaris L. (147.2 pairs), Turdus philomelos Brehm. (128.9 pairs), and Motacilla flava L. (102.3 pairs) are dominant. 50 species of birds are characteristic of artificial forest plantations along the tracks adjacent to water bodies (forest strip 2). The dominant species are Corvus cornix L. (157 pairs), Pica pica L. (150 pairs) Sturnus vulgaris L. (144.4 pairs), and Parus major L. (142.2 pairs).

The ornithocomplex of artificial plantations along the tracks bordering on settlements and anthropogenic structures (forest strip 3) is represented by 44 species. The dominant species are Hirundo rustica L. (163 pairs), Parus major L. (161.4 pairs), Pica pica L. (157.7 pairs), Corvus cornix L. (156.9 pairs), Passer domesticus L , (129.9 pairs) and others. Jacquard's and Sorensen's similarity coefficients were used to analyze the ornithocomplex. The indicators of the determined coefficients indicate the similarity of the species composition of birds of different types of forest plantations along the railway tracks. A high similarity is observed between the artificial plantations along the tracks bordering the agrocenosis and artificial plantings along the tracks bordering settlements and anthropogenic structures (Jacquard's coefficient is 0.91 and Sorensen's similarity coefficient is 0.95 , respectively).

Key words: artificial plantings along the tracks, number of birds, ornithocenosis, population estimation, anthropogenic impact.

Стаття надійшла 20. 10. 2020 р. Рекомендована до друку на засіданні редакиійної колегї̈ після рецензування 